\title{
Perspectives
}

\section{Review: Provider Practice and User Behavior Interventions to Improve Prompt and Effective Treatment of Malaria: Do We Know What Works?}

\author{
Lucy A. Smith,* Caroline Jones, Sylvia Meek, and Jayne Webster \\ Disease Control and Vector Biology Unit, Department of Infectious and Tropical Diseases, London School of Hygiene and \\ Tropical Medicine, Keppel Street, London WC1E 7HT, United Kingdom; Malaria Consortium, Development House, \\ 56-64 Leonard Street, London EC2A 4LT, United Kingdom
}

\begin{abstract}
Effective case management of uncomplicated malaria is a cornerstone of successful malaria control. With current calls for the global elimination of malaria, all strategies to control malaria need to reach the highest achievable level of effective implementation. A systematic literature review of all interventions to improve provider- and/or userside behavior in the prompt and appropriate treatment of uncomplicated malaria (with appropriate evaluation design and Roll Back Malaria outcome indicators) found 23 studies for review. Only 16 studies targeted providers, nine in the public sector and seven in the private sector. Just four interventions were conducted at national scale. These data suggest that very little is known about what interventions work in improving prompt and effective treatment of malaria. In the context of scaling up effective malaria control and malaria elimination plans and in increasing access to artemisinin combination therapies (ACTs), increased research in this area is crucial.
\end{abstract}

\section{INTRODUCTION}

Malaria is one of the leading causes of mortality worldwide, with over ninety percent of the burden falling on sub-Saharan Africa where it causes an estimated one million deaths each year; around seventy-five percent of these deaths are among children under five years of age. ${ }^{1}$

Over the past few years there has been a substantial increase in the amount of attention and funding focused on attempts to reduce the burden of the disease and this focus has been accompanied by the development of various short and medium term targets for intervention coverage and disease reduction. The most recent development has been a call by the Bill and Melinda Gates Foundation, supported by the Director General of the World Health Organization, ${ }^{2}$ to revive the long-term goal of malaria eradication. To start on the path toward achieving this goal, all of the current strategies available to control malaria need to reach the highest level of effective implementation, as outlined in the Global Malaria Action Plan and endorsed at the high level UN Millennium Development Goals meeting held in New York on 25 September. ${ }^{3}$ One of the strategies that has been a corner stone of malaria control for the past 15 years is the prompt and effective treatment of episodes of malaria illness. For this particular strategy, the Roll Back Malaria Partnership (RBM) has set the target for 2010 of " $80 \%$ of malaria patients are diagnosed and treated with effective anti-malarial medicines, e.g., artemisinin-based combination therapies (ACT), within one day of the onset of illness." 4

Data on progress toward this goal are fairly scarce, but information in the 2008 World Malaria Report suggest that the mean proportion of children under five years of age with a fever that were treated with an anti-malarial drug in sub-Saharan Africa between 2006 and 2007 was 38\%, although this varied across countries from $10 \%$ to $63 \%$; just $3 \%$ of children were given ACT (range, $0.1-13 \%) .{ }^{5}$ In addition, a large proportion of these treat-

* Address correspondence to Lucy A. Smith, Disease Control and Vector Biology Unit, Department of Infectious and Tropical Diseases, London School of Hygiene and Tropical Medicine, Keppel Street, London WC1E 7HT, United Kingdom. E-mail: Lucy.Smith@lshtm.ac.uk ments were not started within 24 hours of the onset of fever, and may not therefore have been sufficiently timely to reduce the risk progression into severe life-threatening malaria.

Because prompt and effective treatment was first proposed as a malaria control strategy by the World Health Organization (WHO), ${ }^{6}$ many interventions aimed at the various factors that influence prompt and effective treatment have been developed and implemented. These include interventions aimed at improving the prescription and dispensing practices of providers (public and private, formal and informal), and interventions aimed at the purchasing and adherence practices of anti-malarial users and their caretakers. However, although many interventions have been implemented, the data from the World Malaria Report suggest that there is still some way to go before the RBM target for prompt and effective treatment is met.

Recent reviews have provided information on the factors that influence treatment seeking behavior ${ }^{7}$ and behavior of certain categories of healthcare providers, ${ }^{8-10}$ but to date no over-arching comparison has been made of the relative effectiveness of the various interventions to improve these behaviors or their resulting impact on the diagnosis and effective treatment of patients with malaria within the first day of their illness. If we want to reach the RBM targets, we first need to identify those interventions that are most successful at improving access to prompt and effective malaria diagnosis and treatment. The aim of this study is to conduct a systematic review of current evidence to identify those provider and user behavior interventions that are most effective in improving prompt and effective treatment of malaria.

\section{METHODS}

A systematic search of the published literature was conducted using all combinations of the following search terms in the electronic databases PubMed, CAB Abstracts, African Journals Online, IBSS, and PsychINFO: malaria, fever, febrile, treatment, provider*, health personnel, home management, caretaker*, use*, intervention*, adherence, compliance, knowledge attitude practice, Africa. The last full search was conducted May 2007, although e-mail updates of potentially relevant articles continue to be received from Pubmed and 
RBM. No further papers were included in the review after March 2008. The grey literature was accessed by searching websites of development agencies and organizations running malaria or health system strengthening projects/programs in sub-Saharan Africa.

All references were imported into the reference manager program EndNote 11 and any duplicates removed. The titles and abstracts of these references were checked for relevance and kept if they appeared to meet the objectives of the review. The remainder was read in full and reference lists of each paper were also cross-checked for additional relevant studies. Papers and reports were included only if they involved interventions designed to improve prompt and effective treatment of uncomplicated malaria or febrile illness through changes in anti-malarial provider and/or user behavior. The interventions may have been targeted at treatment of malaria alone, or in combination with other diseases. Papers were excluded if they did not relate to malaria treatment, reported on severe malaria only, covered surveys of provider or user behavior without any intervention, related to chemoprophylaxis, mass drug administration, or traveler health.

Providers were defined as those responsible for dispensing anti-malarials and were further categorized as public and private, and formal and informal or community-based. Public providers were those that operated within the governmental health service; private providers working in the for-profit or non-governmental (NGO) sectors, independent of government funding. For the purposes of this review, formal public providers included health personnel: doctors, medical officers, nurses, and midwives; community-based public providers were voluntary members of the community, including community health workers or motivators (CHWs), schoolteachers, and mothers (Figure 1). Formal private providers were those that possess education and professional training, such as doctors, nurses, and pharmacists operating in the private-forprofit or NGO sectors. Informal private providers were drug vendors, chemical sellers, and general shopkeepers that stock and sell medicines with or without regulation. Users were defined as consumers of anti-malarials; in the case of children under five years of age this also included their caretakers as appropriate.

To evaluate the outcomes, only studies with appropriate evaluation designs were included. Appropriate evaluation designs were defined as randomized controlled trials (RCTs), pre-post design with a control group, time series or repeated measure surveys, ${ }^{11}$ pre-post study evaluations without a control group, and post-only evaluations with a control. These last

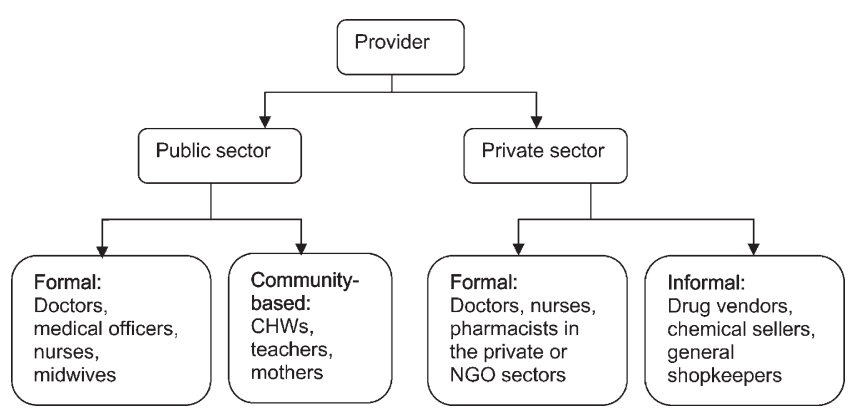

FIGURE 1. Public and private sector formal and informal/ community-based providers.
Box 1

Inclusion criteria

1) Interventions aimed at providers or users designed to improve prompt and effective treatment of fever in children under five years of age.

2) Interventions were targeted at provider and/or user knowledge and/or practices.

3) Studies were evaluated using randomized controlled trials (RCTs), times series measurement, pre-post design with or without a control group, and post design with a control.

4) Reported on at least one element of the Roll Back MalariaMonitoring and Evaluation Reference Group (RBMMERG) indicator on prompt and effective treatment.

5) Presented both numerator and denominator information for outcomes.

two designs were included as it is possible to conclude that the intervention was plausible, or at least adequate, to achieve the outcomes measured even though in the absence of controlling for all potential confounders the designs are not strong enough to infer direct causality between intervention and outcome (as would be the case with a randomizedcontrolled "probability" design). ${ }^{12}$ Studies with evaluations conducted post-intervention only without a control group were excluded. ${ }^{11}$

A standardized checklist was used to extract data from studies on malaria treatment outcomes measured before, during, and after implementation of the intervention. The information extracted was based on the RBM-MERG (Monitoring and Evaluation Reference Group) indicator for early diagnosis and prompt treatment of malaria, which is "the percentage of patients with uncomplicated malaria getting correct treatment at health facility and community levels, according to the national guidelines, within 24 hours of onset of symptoms."13 "Correct treatment" was further divided into its component parts of correct anti-malarial (AM) given, at correct dosage and for the correct duration (according to national guidelines at the time of the study). We interpreted community level to include shops because these are an important source of anti-malarials outside of health facilities. Summary inclusion criteria are presented in Box 1.

\section{RESULTS}

A total of 769 papers were identified from the electronic database searches, of which 48 involved an intervention on prompt and effective treatment of fever (Figure 2). A further 10 such reports on intervention programs were identified from the grey literature. These 58 publications and reports involved a total of 63 study sites, as some studies involved multiple countries $^{14-16}$ or multiple sites in the same country. ${ }^{16}$ Appropriate evaluation designs for assessing outcomes of the interventions were used in 40 of these 63 study sites. Twenty-seven of these 40 studies reported their outcomes in the format of at least some part of the RBM-MERG indicator for early diagnosis and prompt treatment of malaria; four studies were excluded because of a lack of information on the number of the target group sampled (that is, the denominator used in assessing the outcome). The findings of the 23 studies, meeting all inclusion criteria, are summarized in Table 1.

One study was targeted at adults only,${ }^{17}$ four targeted all age groups ${ }^{18-21}$ and the remaining 18 were targeted at children (13 specifically at children under five years of age) ${ }^{14,15,22-32}$ However, most studies reported results in terms of child treatment 


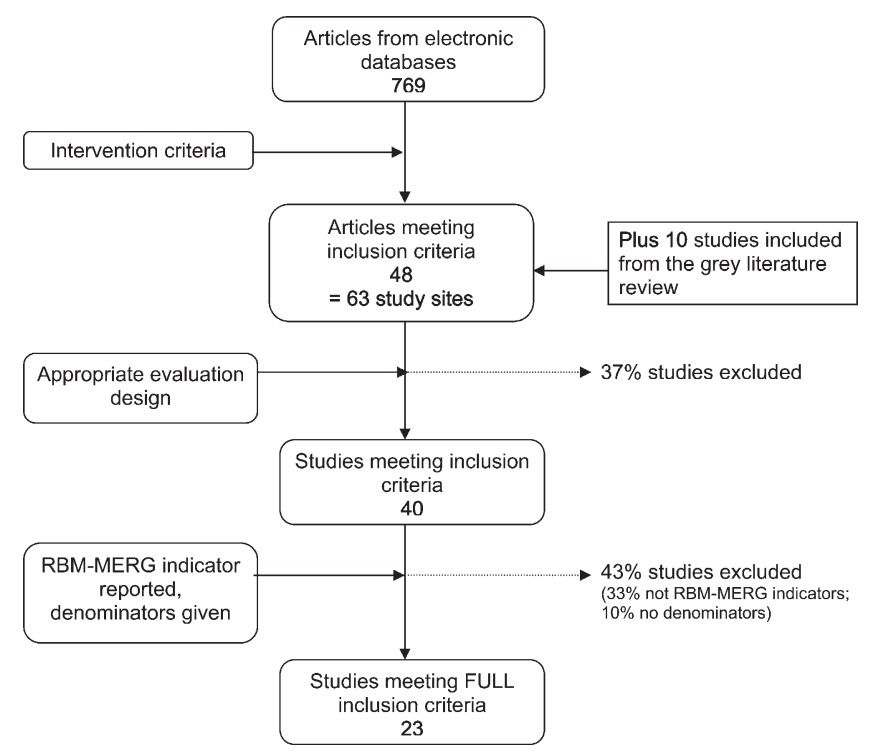

Figure 2. Overview of the study inclusion process.

practices; this is what is reported in Table 1, with the exception of the one adults only study.

Measurement of full "prompt and effective treatment." Only two of the 23 studies reported the full RBM-MERG indicator, including a prompt treatment seeking dimension, and each of these reported on treatment within 24 hours of the onset of symptoms (see Table 1). ${ }^{28,33}$ The first of these is the Kilifi Shopkeeper Training program, which targeted both provider and user behavior. Impressive improvements in shopkeeper prescribing practices were achieved through training on the correct AM dispensing within the context of a change in AM policy from chloroquine (CQ) to sulfadoxine-pyrimethamine (SP) in Kenya. The proportion of shopkeepers prescribing the correct $\mathrm{AM}$ at the correct dose and duration increased from $0 \%$ pre-intervention to $98 \%$ post-intervention $(P<0.001){ }^{33}$ The increase in prompt treatment seeking and adherence among users, through improved counseling by shopkeepers and community sensitization events, was important but not as high $(1.5 \%$ to $27.8 \% ; P<0.001)$. The second study reporting results in the full RBM-MERG indicator format is an evaluation of Uganda's national Home-Based Management of Fever (HBMF) program. This program was also targeted at improving provider and user behavior through the recruitment and training of community drug distributors (CDDs). The CDDs' role is to presumptively treat fever in children under five years of age with free pre-packaged CQ-SP (Homapak) and educate mothers on correct treatment, and what to do if the child's condition worsens. Evaluation of this program as it was rolled out in Kasese district showed a $13.5 \%$ increase in effective treatment among the intervention group $(P=0.01){ }^{28}$

Composite measurement of effective treatment (correct AM, dose, and duration). Nine studies reported on a combination of three components of the RBM-MERG indicator, that is, appropriate anti-malarial given at the correct dose and for the correct duration (see Table 1).

Of these, three studies were targeted at improving the behavior of formal providers. Two of these were within the public sector and involved evaluations of Integrated Management of Childhood Illness (IMCI). ${ }^{14,15}$ Both showed significantly higher levels of appropriate treatment of malaria in the facilities that had received the intervention compared with non-intervention facilities, although the improvements were greater in Tanzania ( $88 \%$ versus $25 \%)^{14}$ than Uganda (49\% versus $\left.24 \%\right) .{ }^{15}$ The other study involved the private sector, ${ }^{17}$ specifically a oneday seminar on rational drug use for private physicians, which achieved an overall increase in appropriate treatment of $9 \%$ by physicians receiving the intervention, although even this modest improvement was of borderline significance.

Three of the nine composite indicator studies focused on interventions aimed at improving user adherence and therefore reported on user practices only. The intervention that involved pre-packaging anti-malarials produced impressive improvements in user practices, achieving full adherence in $91 \%$ of the intervention group, compared with $42 \%$ of the control $(P<0.001)$, by the use of pre-packaged CQ tablets rather than the CQ syrup usually given for small children. ${ }^{22}$ Conversely, the study by Okonkwo and others ${ }^{29}$ showed that appropriate dosing and adherence could be achieved with CQ syrup by the inclusion of a pictorial insert describing the age-specific treatment regimen (full adherence of 52\% with pictorial insert, compared with $37 \%$ without). When verbal instructions were also given alongside the pictorial insert, even greater improvements were achieved (further increasing adherence to $73 \%$ ). This supports the need for clear visual and verbal instructions to be given with any drug treatment if it is to be taken correctly.

The third study was an RCT showing that supervised treatment with chloroquine at the health facility achieved $86 \%$ full adherence, compared with $60 \%$ when treatment was given unsupervised at home. ${ }^{25}$ Interestingly, there was no significant difference in treatment outcome, leading the investigators to conclude that mothers in this part of Guinea Bissau could "be trusted to give adequate anti-malarial medication to their children at home." 25

The remaining three composite indicator studies targeted both providers and users. All three involved public providers, one formal sector ${ }^{21}$ and two community-based..$^{20,34}$ The study by Winch and others in Mali ${ }^{20}$ had separate components targeted at the two groups, training providers (drug kit managers) in appropriate presumptive treatment of fever in children under five years of age (or referral of severe cases), with accompanying community sensitization and education activities targeted at the users to increase their awareness and demand for the service. The additional training provided to the drug kit managers in the intervention areas produced marginal improvements in provider behavior, compared with the basic training provided in the control areas (59\% and $48 \%$, respectively; $P=0.042)$. However, the improvements were much greater in user behavior ( $42 \%$ full adherence in intervention area, compared with $1.5 \%$ in control; $P<0.001)$.

The other two studies involved training providers to improve both their own practice and encourage adherence of their patients. $^{21,34}$ The study by Yeboah-Antwi and others ${ }^{21}$ involved the use of pre-packaged drugs and resulted in appropriate treatment by $93.3 \%$ of intervention group providers (compared with $73.5 \%$ of control providers, $P<0.001$ ) and $82 \%$ of intervention group users (compared with $60.5 \%$ of control users, $P<0.001$ ). The study by Afenyadu and others ${ }^{34}$ built upon an existing and effective scheme of teachers trained to administer drugs to presumptively treat fever in school children. The introduction of pre-packaged drugs further increased the correct 
TABLE 1

Summary of study outcomes according to the RBM-MERG case management indicator

\begin{tabular}{|c|c|c|c|c|c|c|}
\hline Recipient(s) & Intervention & $\begin{array}{c}\text { Scale of } \\
\text { implementation }\end{array}$ & $\begin{array}{l}\text { Evaluation } \\
\text { design (period } \\
\text { after int) }\end{array}$ & $\begin{array}{l}\text { Single components of RBM-MERG } \\
\text { indicator (Correct AM, or dose, or } \\
\text { duration) }\end{array}$ & $\begin{array}{l}\text { Composite RBM-MERG } \\
\text { indicator (Correct AM, } \\
\text { dose and duration, unless } \\
\text { otherwise indicated) }\end{array}$ & $\begin{array}{l}\text { Country and } \\
\text { year of study }\end{array}$ \\
\hline \multirow[t]{4}{*}{$\begin{array}{l}\text { Public formal } \\
\text { providers }\end{array}$} & $\begin{array}{l}\text { Client-oriented, provider } \\
\text { efficient (COPE) } \\
\text { services. Provider-led } \\
\text { self-assessment and } \\
\text { planning. }\end{array}$ & Sub-district & $\mathrm{P}+\mathrm{C}(0 \mathrm{mo})$ & $\begin{array}{l}\text { I/C (AM) Int: } 61.9 \% \\
\quad \text { (99/160), Comp: 50.7\% } \\
\quad(81 / 160)(P=0.06)\end{array}$ & & $\begin{array}{l}\text { Guinea, } \\
\text { Kenya, } \\
2001^{35}\end{array}$ \\
\hline & $\begin{array}{l}\text { Integrated management } \\
\text { of childhood illness } \\
\text { (IMCI). }\end{array}$ & National & $\begin{array}{l}\mathrm{P}+\mathrm{C} \\
\quad(\max 3 \mathrm{yrs})\end{array}$ & & $\begin{array}{l}\text { I/C Int: } 88 \%(149 / 169), \\
\text { Comp: 25\% (34/135) } \\
(P<0.001)\end{array}$ & $\begin{array}{l}\text { Tanzania, } \\
2000^{14}\end{array}$ \\
\hline & IMCI. & National & $\mathrm{P}+\mathrm{C}(? ?)$ & & $\begin{array}{l}\text { I/C Int: } 49 \%(68 / 139) \\
\text { Comp: } 24 \%(53 / 221) \\
(P<0.001)\end{array}$ & $\begin{array}{l}\text { Uganda, } \\
2000^{15}\end{array}$ \\
\hline & $\begin{array}{l}\text { In-service training of } \\
\text { medical assistants. Two } \\
\text { hour lecture. }\end{array}$ & National & $\begin{array}{l}\mathrm{B} / \mathrm{A}-\mathrm{C} \\
\quad(3-9 \mathrm{mo})\end{array}$ & $\begin{array}{l}\text { B/A (Dose) } 12.5 \%(4 / 32) \text { to } \\
\quad 30.3 \%(10 / 33)(P=0.1)\end{array}$ & & $\begin{array}{l}\text { Ghana, } \\
1987^{18}\end{array}$ \\
\hline $\begin{array}{l}\text { Private formal } \\
\text { providers }\end{array}$ & $\begin{array}{l}\text { One-day seminar on } \\
\text { rational drug use } \\
\text { (targeting adults only). }\end{array}$ & Sub-district & $\begin{array}{l}\mathrm{B} / \mathrm{A}+\mathrm{C} \\
\quad(0 \mathrm{mo})\end{array}$ & & $\begin{array}{l}\text { B/A+C Int: } 13 \%(4 / 30) \\
\quad \text { to } 27 \%(8 / 30) \text { Cont: } 28 \% \\
\text { (22/78) to 33\% }(26 / 78) \\
\quad+9 \% \text { in intervention } \\
\text { group }(P=0.09)\end{array}$ & $\begin{array}{l}\text { Uganda, } \\
? ?^{17}\end{array}$ \\
\hline \multirow[t]{4}{*}{$\begin{array}{l}\text { Private informal } \\
\text { providers }\end{array}$} & $\begin{array}{l}\text { One-hour 1-to-1 session } \\
\text { for drug sellers. }\end{array}$ & Sub-district; & $\begin{array}{l}\mathrm{B} / \mathrm{A}+\mathrm{C} \\
\quad(7 \mathrm{mo})\end{array}$ & $\begin{array}{l}\text { B/A+C (AM) Int: } 60 \% \\
(12 / 20) \text { to } 100 \%(20 / 20) \\
\text { Cont: } 40 \%(8 / 20) \text { to } 60 \% \\
(12 / 20) .+20 \% \text { in interven- } \\
\text { tion group }(P=0.02) .\end{array}$ & & $\begin{array}{l}\text { Tanzania, } \\
2004^{27}\end{array}$ \\
\hline & $\begin{array}{l}\text { One-day training } \\
\text { PMVs by peers }+ \\
\text { pre-packaged AMs. }\end{array}$ & District & $\begin{array}{l}\mathrm{B} / \mathrm{A}-\mathrm{C} \\
\quad(4 \mathrm{mo})\end{array}$ & $\begin{array}{l}\text { B/A (AM) } 48 \%(54 / 112) \\
\text { to } 87 \%(87 / 100) \\
(P<0.001) . \mathbf{B} / \mathbf{A} \\
\text { (Dose) } 11 \%(12 / 112) \\
\text { to } 57 \%(57 / 100) \\
(P<0.001) .\end{array}$ & & $\begin{array}{l}\text { Nigeria, } \\
2003^{23}\end{array}$ \\
\hline & $\begin{array}{l}\text { Negotiation sessions } \\
\text { (based on self- } \\
\text { assessment and } \\
\text { action planning). }\end{array}$ & District & $\begin{array}{l}\mathrm{B} / \mathrm{A}-\mathrm{C} \\
\quad(1-3 \mathrm{mo})\end{array}$ & $\begin{array}{c}\text { B/A (AM) } 2 \%(1 / 57) \text { to } \\
73 \%(48 / 66)(P<0.001) \\
\text { B/A (Dose) } 0-50 \% \\
(33 / 66)(P<0.001)\end{array}$ & & $\begin{array}{l}\text { Uganda, } \\
2003^{32}\end{array}$ \\
\hline & $\begin{array}{l}\text { Drug vendor-to-vendor } \\
\text { education. }\end{array}$ & District & $\mathrm{P}+\mathrm{C}(6 \mathrm{mo})$ & $\begin{array}{l}\text { I/C (AM) Int: } 24 \%(37 / 157), \\
\text { Comp: } 3 \%(6 / 202) \\
(P<0.001) \text { I/C (Dose) } \\
\text { Int: } 17 \%(27 / 157), \text { Comp: } \\
1.5 \%(3 / 202)(P<0.001)\end{array}$ & & $\begin{array}{l}\text { Kenya, } \\
2000^{31,36}\end{array}$ \\
\hline \multirow[t]{6}{*}{ Users only } & $\begin{array}{l}\text { RCT of pre-packaged } \\
\text { CQ tablets vs. CQ } \\
\text { syrup. }\end{array}$ & Sub-district & RCT (0 mo) & & $\begin{array}{l}\text { I/C Int: } 91 \%(141 / 155) ; \\
\text { Cont: } 42 \%(61 / 144) \\
\text { syrup }\left(\mathrm{X}^{2}=78.3\right. \\
P<0.001)\end{array}$ & $\begin{array}{l}\text { Ghana, } \\
? ?^{22}\end{array}$ \\
\hline & $\begin{array}{l}\text { Village health motivators } \\
\text { and drug vendors } \\
\text { trained to educate } \\
\text { mothers. }\end{array}$ & Sub-district & $\mathrm{B} / \mathrm{A}+\mathrm{C}(? ?)$ & $\begin{array}{l}\text { B/A+C, knowledge only } \\
\text { (Dose: CQ for } 1-3 \\
\text { years) Int: } 23.2 \%(80 / 345) \\
\text { to } 58.8 \%(203 / 345) \text { Cont: } \\
20 \%(46 / 230) \text { to } 14.8 \% \\
(34 / 230) .+40.8 \% \text { in } \\
\text { intervention group } \\
(P<0.001)\end{array}$ & & $\begin{array}{r}\text { Zambia, } \\
2000^{24}\end{array}$ \\
\hline & $\begin{array}{l}\text { Supervised vs. unsuper- } \\
\text { vised treatment. }\end{array}$ & Sub-district & RCT (0 mo) & & $\begin{array}{l}\text { I/C Int: } 86 \%(56 / 65) \\
\quad \text { Cont: 60\% }(41 / 68) \\
\quad(P<0.001) .\end{array}$ & $\begin{array}{l}\text { Guinea } \\
\text { Bissau, } \\
1995^{25}\end{array}$ \\
\hline & $\begin{array}{l}\text { Health education program } \\
\text { for mothers. }\end{array}$ & Sub-district & $\begin{array}{l}\mathrm{B} / \mathrm{A}-\mathrm{C} \\
\quad(3 \mathrm{mo})\end{array}$ & $\begin{array}{l}\text { B/A, knowledge only (AM) } \\
2.3 \%(3 / 120) \text { to } 90 \% \\
(103 / 114)(P<0.001)\end{array}$ & & $\begin{array}{l}\text { The } \\
\text { Gambia, } \\
1986^{37}\end{array}$ \\
\hline & $\begin{array}{l}\text { Village health education } \\
\text { meetings; free treatment } \\
\text { at health post. }\end{array}$ & Sub-district & $\begin{array}{l}\mathrm{B} / \mathrm{A}-\mathrm{C} \\
\quad(12 \mathrm{mo})\end{array}$ & $\begin{array}{l}\text { B/A, knowledge only (AM) } \\
50 \%(92 / 185) \text { to } 81.7 \% \\
(98 / 120)(P<0.001) .\end{array}$ & & $\begin{array}{l}\text { Cameroon, } \\
? ?^{26}\end{array}$ \\
\hline & $\begin{array}{l}\text { Three-armed RCT: CQ } \\
\text { syrup only (control), } \\
\text { CQ syrup with pictorial } \\
\text { insert, CQ syrup } \\
\text { with pictorial insert } \\
\text { and verbal instructions. }\end{array}$ & Sub-district & RCT (0 mo) & & $\begin{array}{l}\text { B/A Control } 36.5 \% \\
\text { (69/190); pictorial } \\
\text { insert 51.9\% (117/225); } \\
\text { insert and verbal } \\
\text { instructions } 73.3 \% \\
(159 / 217) . \mathrm{X}^{2} \text { tests } \\
\text { all significant at the } \\
0.1 \% \text { level. }\end{array}$ & $\begin{array}{l}\text { Nigeria, } \\
1996^{29}\end{array}$ \\
\hline
\end{tabular}


TABLE 1

Continued

\begin{tabular}{|c|c|c|c|c|c|c|}
\hline Recipient(s) & Intervention & $\begin{array}{c}\text { Scale of } \\
\text { implementation }\end{array}$ & $\begin{array}{l}\text { Evaluation } \\
\text { design (period } \\
\text { after int) }\end{array}$ & $\begin{array}{l}\text { Single components of RBM-MERG } \\
\text { indicator (Correct AM, or dose, or } \\
\text { duration) }\end{array}$ & $\begin{array}{l}\text { Composite RBM-MERG } \\
\text { indicator (Correct AM, } \\
\text { dose and duration, unless } \\
\text { otherwise indicated) }\end{array}$ & $\begin{array}{l}\text { Country and } \\
\text { year of study }\end{array}$ \\
\hline & $\begin{array}{l}\text { Neighbor-to-neighbor } \\
\text { education. }\end{array}$ & District & $\mathrm{P}+\mathrm{C}(2 \mathrm{mo})$ & $\begin{array}{c}\text { I/C (AM) Int: 49\% (50/103), } \\
\text { Comp: 30\% (27/89) } \\
(P=0.007) \text { I/C (Dose) } \\
\text { Int: } 29 \%(14 / 50), \text { Comp: } \\
16 \%(4 / 27)(P=0.20)\end{array}$ & & $\begin{array}{l}\text { Kenya, } \\
2002^{19}\end{array}$ \\
\hline $\begin{array}{l}\text { Public formal } \\
\text { providers } \\
\text { AND users }\end{array}$ & $\begin{array}{l}\text { RCT of pre-packaged } \\
\text { AM + paracetamol } \\
\text { vs. routine prescribing } \\
\text { methods. }\end{array}$ & Sub-district & RCT (0 mo) & & $\begin{array}{l}\text { I/C Providers Int: } 93.3 \% \\
\text { (293/314); Cont: } 73.5 \% \\
\text { (250/340) }(P<0.001) \\
\text { I/C Users Int: } 82 \% \\
\text { (137/167); Cont: 60.5\% } \\
\text { (92/152) }(P<0.001) .\end{array}$ & $\begin{array}{l}\text { Ghana, } \\
\quad ? ?^{21}\end{array}$ \\
\hline \multirow[t]{4}{*}{$\begin{array}{l}\text { Public informal } \\
\text { providers } \\
\text { AND users }\end{array}$} & $\begin{array}{l}\text { RCT of pre-packaged } \\
\text { vs. loose CQ, given } \\
\text { by schoolteachers for } \\
\text { presumptive treatment } \\
\text { of fever. }\end{array}$ & District & RCT (0 mo) & & $\begin{array}{l}\text { I/C Providers Int: } 97 \% \\
\quad(294 / 303) ; \text { Cont: } \\
86.6 \%(206 / 238) \\
(P<0.001) . \text { I/C Users } \\
\text { Int: } 88.5 \%(101 / 114) \\
\text { I; Cont: } 88.9 \%(48 / 54) \\
(P=0.94)\end{array}$ & $\begin{array}{l}\text { Ghana, } \\
1998^{34}\end{array}$ \\
\hline & $\begin{array}{l}\text { Training village drug kit } \\
\text { managers. }\end{array}$ & District & $\mathrm{RCT}(1-3 \mathrm{mo})$ & & $\begin{array}{l}\text { I/C Providers Int: } 59 \% \\
\text { (89/151), Comp: } 48 \% \\
\text { (63/131) }(P=0.042, \\
\text { adj) I/C Users Int: } \\
42 \%(64 / 151), \text { Comp: } \\
1.5 \%(2 / 131)(P<0.001, \\
\text { adj) }\end{array}$ & $\begin{array}{l}\text { Mali, } \\
\quad 2001^{20}\end{array}$ \\
\hline & $\begin{array}{l}\text { Training mother educators } \\
\text { to empower other } \\
\text { women + pre-packaged } \\
\text { drugs available from } \\
\text { CHWs. }\end{array}$ & Province & $\begin{array}{l}\mathrm{B} / \mathrm{A}-\mathrm{C} \\
\quad(12 \mathrm{mo})\end{array}$ & $\begin{array}{l}\text { B/A Users (AM) } 25 \% \\
(94 / 377) \text { to } 46 \%(175 / 380) \\
(P<0.001) . \mathbf{B} / \mathbf{A} \text { Users } \\
\text { (Dose) } 3 \%(3 / 94) \text { to } 49 \% \\
(86 / 175)(P<0.001) . \mathbf{B} / \mathbf{A} \\
\text { Users (Duration) } 21 \% \\
(20 / 94) \text { to } 72 \%(126 / 175) \\
(P<0.001)\end{array}$ & & $\begin{array}{l}\text { Burkina } \\
\text { Faso, } \\
1994^{30}\end{array}$ \\
\hline & $\begin{array}{l}\text { Use of CDDs to educate } \\
\text { mothers + free } \\
\text { pre-packaged drugs. }\end{array}$ & National & $\begin{array}{l}\mathrm{B} / \mathrm{A}+\mathrm{C} \\
\quad(18 \mathrm{mo})\end{array}$ & & $\begin{array}{l}\text { B/A+C* Users Int: } \\
\quad 7.4 \%(12 / 163) \text { to } \\
13.5 \%(21 / 156) \text { Cont: } \\
7.3 \%(7 / 96) \text { to } 0 \% \\
(0 / 76) .+13.5 \% \text { in } \\
\text { intervention group } \\
(P=0.01)\end{array}$ & $\begin{array}{l}\text { Uganda, } \\
2004^{28}\end{array}$ \\
\hline \multirow[t]{2}{*}{$\begin{array}{l}\text { Private informal } \\
\text { providers } \\
\text { AND users }\end{array}$} & $\begin{array}{l}\text { Training on correct AM } \\
\text { dispensing practices } \\
\text { and communication } \\
\text { with clients. }\end{array}$ & Sub-district & $\mathrm{B} / \mathrm{A}-\mathrm{C}(2 \mathrm{mo})$ & $\begin{array}{l}\text { B/A Providers (Dose) } \\
31.8 \%(31 / 99) \text { to } 82.7 \% \\
(165 / 199) ; \text { to } 89.9 \% \\
(107 / 119) \text { after refresher } \\
\text { training }(P<0.001) . \text { B/A } \\
\text { Users, knowledge only } \\
\text { (Dose) } 3.7 \%(4 / 109) \text { to } \\
65.2 \%(118 / 181) \text {; to } 75 \% \\
(81 / 108) \text { after refresher } \\
(P<0.001) \text {. }\end{array}$ & & $\begin{array}{l}\text { Kenya, } \\
1996^{40}\end{array}$ \\
\hline & $\begin{array}{l}\text { Training on correct AM } \\
\text { dispensing practices } \\
\text { and communication } \\
\text { with clients + policy } \\
\text { change from CQ to SP. }\end{array}$ & Sub-district & $\begin{array}{l}\mathrm{B} / \mathrm{A}-\mathrm{C} \\
\quad(12 \mathrm{mo})\end{array}$ & & $\begin{array}{l}\text { B/A Providers } 0-98 \% \\
\quad \text { (96/98) }(P<0.001) . \\
\text { B/A Users* Sub- } \\
\text { location: } 3 \%(13 / 388) \\
\text { to } 27 \%(78 / 287) \\
(P<0.001) . \text { All areas: } \\
1.5 \%(10 / 681) \text { to } 27.8 \% \\
(257 / 923)(P<0.001)\end{array}$ & $\begin{array}{l}\text { Kenya, } \\
1999^{33}\end{array}$ \\
\hline
\end{tabular}

* Composite indicator also includes treatment within 24 hours (i.e., the complete RBM-MERG indicator). Abbreviations: adj $=\mathrm{P}$ value adjusted for clustering; $\mathrm{AM}=$ anti-malarial; ARI $=$ acute respiratory infection; $\mathrm{CDD}=$ community drug distributor; $\mathrm{CQ}=$ chloroquine; $\mathrm{CHW}=$ community health worker; $\mathrm{IMCI}=$ integrated management of childhood illness; $\mathrm{PMV}=$ patent medicine vendor; $\mathrm{RCT}=$ randomized controlled trial; $\mathrm{SP}=$ sulfadoxine-pyrimethamine; ? ? = no information on year of study/start of intervention. Evaluation designs: $\mathrm{I} / \mathrm{C}=$ intervention vs. control (or comparison); $\mathrm{B} / \mathrm{A}=$ before (baseline) vs. after implementation; $\mathrm{B} / \mathrm{A}+\mathrm{C}=$ before and after implementation with control; B/A-C $=$ before and after implementation without control; Int $=$ intervention group; Cont $=$ control group; Comp = comparison group.

treatment by teachers from $88.9 \%$ in the control schools to $97 \%$ in the intervention schools $(P<0.001)$. Less impact was seen on adherence by the children taking drugs over the weekend, but this was already high at around $88 \%$.
Measurement of individual components of effective treatment (correct AM, or dose, or duration). Twelve studies reported on one or more of the component parts of the RBMMERG indicator. Specifically, nine reported the correct AM, 
nine the correct dose, one the correct duration; no study separately reported on the prompt treatment seeking component (see Table 1).

Two studies were found that reported on the results of interventions to improve formal provider behavior, both of which were in the public sector. The participatory approach used by Bradley and Igras $^{35}$ achieved borderline significance with $61.9 \%$ of the intervention group prescribing an appropriate anti-malarial, compared with $50.7 \%$ of control group $(P=0.06)$. However, the in-service training delivered in the other study ${ }^{18}$ was of limited effectiveness, perhaps because of the short duration and didactic style of the interventions, which focused on lectures about rational drug use in accordance with the national treatment guidelines.

Three of the four studies found that targeted informal providers (all in the private sector) appeared to produce much better improvements in practice, achieving correct anti-malarial sales in $73-100 \%$ of intervention shops, an increase from low baseline levels. ${ }^{23,27,32}$ This may reflect the more participatory nature of the interventions, which in two of the studies were designed with the input of the drug vendors themselves. ${ }^{23,32}$ Feedback from baseline observations of practice was used to facilitate self-assessment and action planning for performance improvements. Although positive improvements were found in the third study from a one-to-one session of just one-hour duration, ${ }^{27}$ the scale of this study was very small, involving only 20 intervention and 20 control drug vendors.

The fourth study involving informal providers, which used a vendor-to-vendor education program, ${ }^{31,36}$ also showed improvements in provider practice, although of a smaller magnitude; $24 \%$ of intervention outlets dispensed the correct AM to a mystery shopper and $17 \%$ the correct dose, compared with $3 \%$ and $1.5 \%$ of comparison outlets, respectively.

Four studies were found that targeted only users, all of which used a health education approach to improve appropriate treatment seeking for fever. Educating users alone does appear to be effective at changing their knowledge of the appropriate anti-malarial or dosage ${ }^{24,26,37}$ however, it has been frequently shown elsewhere that changes in knowledge do not necessarily correlate with changes in behavior. ${ }^{38,39}$ The impact on actual behavior was only measured in one study, ${ }^{19}$ and this showed significant effects for the use of correct AM $(49 \%$ in the intervention area, compared with $30 \%$ in the nonintervention area); there was no significant difference between intervention and comparison areas for using the correct dose.

A further two interventions were found that involved both providers and users; one involving the community-based public sector, ${ }^{30}$ and one the informal private sector. ${ }^{40}$ Both studies had separate components targeted at the two groups, training of providers in appropriate presumptive treatment of fever in children under five years of age (community health workers/ drug distributors, or private drug sellers), with accompanying community sensitization and education activities targeted at the users to increase their demand for the services provided by trained providers. The inclusion of pre-packaged drugs ${ }^{30}$ or specific training on communication skills ${ }^{40}$ was additional components of the intervention to facilitate appropriate behavior by both providers and users. The approach used by Pagnoni and others $^{30}$ in Burkina Faso was to empower mothers to actively seek the correct treatment for their children, with the CHWs simply holding the drug stocks and referring severe cases. This achieved significant improvements from baseline in use of correct AM (25-46\%), correct dose (3-49\%), and correct duration $(21-72 \%)$. The shopkeeper training program, as reported by Marsh and others, ${ }^{40}$ produced more impressive changes in provider behavior ( $83 \%$ gave correct dose compared with $32 \%$ at baseline) as well as user knowledge (65\% stated correct dose compared with $4 \%$ at baseline). Both of these indicators increased yet further following refresher training 6 months after the initial intervention ( $90 \%$ correct dose given by providers, $75 \%$ correct dose reported by users).

\section{DISCUSSION}

The overwhelming finding from this systematic review is that there are very few data on available interventions to improve the appropriate case management of uncomplicated malaria and even fewer, which have been evaluated in such a manner that the impact can be reasonably ascribed to the intervention. The majority of studies were excluded as they did not report on an intervention, generally reporting instead on current practices of providers ${ }^{41-43}$ and/or users ${ }^{4-46}$; a number of papers found were literature reviews ${ }^{7,11,47,48}$ or related to changing national drug policies ${ }^{49}$ or wider health systems issues. ${ }^{8,50}$ Approximately 37\% (23/63) of studies that did include interventions to improve prompt and effective treatment of malaria were excluded as they did not include an appropriate evaluation method for assessing the outcomes of the intervention.

The authors appreciate the difficulties in conducting evaluations of interventions that may be part of multifaceted programs rather than formally designed experiments, and acknowledge that such evaluations may have certain important lessons to contribute. However, we were concerned with determining the effectiveness of interventions, which demands a certain standard of evaluation design. Studies using post-only with control and pre-post no control designs were included because they provide evidence of the "plausibility" or "adequacy" of an intervention, respectively; in the absence of controlling for all potential confounders the designs are not strong enough to infer direct causality between intervention and outcome (as would be the case with a randomized-controlled "probability" design), however it is possible to conclude that the intervention was plausible, or at least adequate, to achieve the outcomes measured. ${ }^{12}$ If these study designs were excluded, only 24 (rather than 40) interventions would remain (of which 10 would be classed as "probability" studies and 14 as "plausibility"), with the majority of those lost being program evaluations, which are important because they demonstrate the effectiveness of interventions under "real-life" conditions (as opposed to controlled intervention trials).

Our choice to only include studies reporting results in the format of the RBM-MERG indicator reduced the evidence base by a further $43 \%$. It is important to note that a number of the studies (among those both excluded and included by this criterion) were conducted or published before the RBMMERG indicator was developed. However, prompt and effective treatment has been a key malaria control strategy for many years, and we felt the decision was justified given the necessity for all four components (correct AM, correct dose, correct duration, prompt access) to achieve effective case management of uncomplicated malaria. Additionally, the use of a common indicator(s) facilitates comparison of results among studies. Some flexibility in reporting was kept-studies reporting on single components of the indicator were included. Indeed, had 
we only included studies that reported the full indicator (with or without an element of prompt treatment seeking); only 11 studies would have remained for analysis and discussion.

The RBM indicator, although useable for both providers and users, means slightly different things in each group. Among providers the indicator assesses whether the correct anti-malarial is prescribed (based on the national guidelines at the time), and whether it is prescribed at the correct dose and for the correct duration. In users this indicator may be used to assess what was prescribed by the provider, what the user actually received, and whether they completed the treatment (i.e., adhered) at the correct dose in a prompt manner.

The magnitude of impact of the 23 interventions on prompt and effective treatment included in our analysis, varies greatly between the groups targeted, methods used, and scale of intervention.

Overall, only 16 studies were found involving interventions targeted at providers, nine in the public sector and seven in the private sector. Once this is further broken down into formal and informal/community-based providers within each category, the number of studies providing evidence on possible interventions becomes even smaller (Public sector: 5 formal, 4 community-based; private sector: 1 formal, 6 informal).

In-service training of formal providers, using the methods that have been adopted to date, does not appear to have had much impact in the included studies. Often such in-service training uses a didactic approach, presenting the case for rational drug use without accounting for wider determinants of practice, such as patient demand for certain drugs/services, or the influence of peers. ${ }^{51}$ In addition, without follow-up supervision any improvements gained by training have been shown to severely deteriorate within a period of 12 months. ${ }^{18}$ The approach adopted in IMCI training, which involves more interactive learning with the chance for clinical practice, has shown positive, albeit mixed, results. For example, the effectiveness of IMCI on provider treatment of malaria was almost twice as high in Tanzania as in Uganda. Reasons for this may have been quality of training and/or supervision, and other factors such as health worker morale..$^{15}$ Emphasizing rational drug use and improved provider-client communication during pre-service training, as well as on-site refresher training using opinion leaders or district-level staff and supportive supervision, may be more effective methods for improving the case management of malaria in the formal sector. ${ }^{11}$ A series of cross-sectional studies of health worker performance generally found that reported experience of in-service training was not significantly associated with correct treatment of uncomplicated malaria ${ }^{52-54}$; in one of the studies, in-service training was associated with appropriate malaria case management, but only when combined with other interventions such as job aides and frequent supervision. ${ }^{55}$ Similar mixed findings were reported by a wider review of (non-malaria-specific) interventions to improve health-worker performance. ${ }^{56}$ Regardless, any improvements in prescribing practices can only be maintained if adequate supplies of effective anti-malarial drugs are available. ${ }^{57}$ Further investigation of the role and performance of formal private providers in the case management of malaria is particularly needed and, in countries where they are an important source of treatment, increasing their involvement in interventions should be considered.

In general, the interventions targeted at informal providers showed greater impacts on behavior, particularly those involving the private sector, i.e., shopkeepers and drug vendors. The more successful of these involved the drug vendors in the design and content of training, and found that gaining the trust and commitment of informal private providers was extremely important to the program's success, because they operate largely outside the government regulatory framework and can be suspicious of external attention. Our findings support those discussed in a recent review of the role of medicine sellers in malaria treatment by Goodman and others, ${ }^{9}$ namely that successful interventions included buyin from medicine sellers and community members, use of a combination of approaches (including visual job aides such as dosing charts and community sensitization), and maintenance of training and supervision. Informal private providers, such as drug vendors and general shopkeepers, are widely used for fever and malaria treatment in sub-Saharan Africa, often forming the first (and in some cases, only) source of care ${ }^{58}$ Their potential for achieving effective and, particularly, prompt treatment of uncomplicated malaria should not be underestimated.

The common model used in the community-based public sector is that of training community volunteers (including mothers and schoolteachers) in the presumptive treatment of fever in under fives with pre-packaged anti-malarials, coupled with community sensitization activities. Significant but modest improvements in treatment behavior have been shown; however, there is still considerable room for improvement in this approach. To realize the potential of $\mathrm{CHW}$ programs, there must be sufficient training and supervision, as well as sufficient payment or incentives for their health extension work, particularly as their tasks and responsibilities are increased. ${ }^{59}$ Interestingly, the study involving schoolteachers was highly effective in improving both user and provider practiceperhaps because of the authoritative nature of the teacherpupil relationship and structured school environment.

Fourteen of the interventions had at least some component targeting users, seven involving users only and seven also including a provider-side component. As presented in the results section, two general approaches to improving user malaria treatment practices have been used: 1) health education messages or campaigns, and 2) interventions that specifically provide information on how to take prescribed/dispensed anti-malarials, including pre-packaging, and pictorial and verbal instructions. The second of these approaches has achieved much greater improvements in behavior, indeed the health education programs were generally only evaluated in terms of changes in knowledge, which is insufficient when change in practice is the ultimate goal.

Our analysis suggests that, among the included studies, pre-packaging of drugs is one of the most effective ways of increasing adherence to guidelines by both users and providers in all sectors. A recent Cochrane review, ${ }^{60}$ evaluating the effectiveness of unit dose packaged treatments for malaria on cure and treatment adherence, found insufficient evidence to determine the effectiveness of unit dose packaging on treatment outcomes, but some evidence to suggest that the unit dose packaging together with prescriber training and patient information did improve patient adherence. However, the authors cautioned that the data were derived from studies with methodological limitations.

Where significant changes in behavior have been measured, only two studies provide information on the full RBM-MERG 
indicator and in these studies the changes, although significant, still leave at least two thirds of the population without prompt, effective treatment (including dose and duration), well short of the $80 \%$ RBM target for 2010 . These findings have significant implications not only for individual morbidity and mortality, but also for broader public health efforts to eradicate malaria. That is, unless individuals who are ill with malaria are able to promptly access the correct treatment and complete an adequate dose then the individual is at risk of severe illness and death, and parasites continue to circulate in the population.

A further concern is the sustainability of behavior change. Many of the post-intervention surveys were carried out immediately or very soon after the training or intervention had been conducted (16 of 21 studies with this information were completed within 12 months of the intervention, 12 within 3 months; see Table 1). It is possible that some of the changes in behavior and/or knowledge would lose significance if measured again, for example a year later. Sustainability of behavior change is crucial if the intervention is to provide any lasting benefits. A number of the studies implemented their interventions with sustainability in mind and conducted longer duration followup. For example, the Shopkeeper Training Program in Kilobit conducted annual refresher workshops and found a sustained improvement in provider practices with $98 \%$ fully adhering to treatment guidelines up to 4 years after the program started. User knowledge was also sustained, but unfortunately the long-term practices of users were less impressive with only $27 \%$ fully adhering by the end of the study. ${ }^{33}$ The Homapak study in Uganda was conducted 18 months after implementation, and supports the need for activities to improve the longer-term impact with only $13.5 \%$ of the study population accessing a complete course of effective anti-malarials within 24 hours of onset of symptoms. ${ }^{28}$ However, because no indication of CDD performance was reported, it is unclear whether this was a result of sub-optimal performance of the CDDs or lack of appropriate sensitization and education of the communities. It is possible that the modest impact is related to the constraints accompanying implementation of the intervention at national scale, e.g., a lack of personnel to provide adequate supervision and sensitization. The CHW training in Burkina Faso showed significant improvements in user adherence when the supply chain and supervision was still under the management of the research team, but was seriously impeded when handed over to the routine health system and problems with stock-outs were experienced. ${ }^{30}$ These findings reinforce the notion that any interventions to change provider and user behavior need to take account of the broader context within which these changes are being implemented (e.g., staff constraints, supply constraints, access constraints).

A final issue that arises from this review is the scope of implementation of the interventions. Only four of the included studies involved interventions implemented at the national scale. In the case of the HBMF and IMCI interventions, the studies were evaluating a national strategy using a districtlevel phased-in approach. Although a number of the studies were carried out at district level, which in many countries is now the level of implementation of national policy, there is still a need for national-level co-ordination and supervision, especially given the wide variation in capacity between different districts within a country. This is of particular relevance in the context of elimination discussions because high levels of effective case management (in combination with other strategies) will need to be achieved and maintained nationally (and indeed regionally); a country cannot afford to have poorly performing districts or neighbors.

\section{CONCLUSION}

The importance of improving effective case management of malaria in the context of intensive malaria control and elimination cannot be overestimated. The results from this review show that many interventions aimed at improving malaria case management have been undertaken, but assessment of their effectiveness is severely constrained by limitations in the methods used to evaluate their success. In order that lessons from future programs might provide evidence on the effectiveness of alternative interventions, the methods used to evaluate these interventions should be sufficient to assign at least adequacy that the intervention has contributed to an increase in the relevant outcome, or plausibility that improved outcomes were a result of the intervention.

Making definitive conclusions from the findings of this review on "best" interventions is difficult, given the diversity of groups targeted, scale of implementation, and evaluation designs and methods used. It is clear that while some effective interventions to improve malaria treatment do exist, significantly more information is needed to provide definitive evidence. In particular, there is a large gap in the evidence on "what works" to change formal public and private sector provider behavior and even less evidence is available on how to sustain any behavior change achieved. Although we recognize the need to increase access to effective anti-malarial through the community and the retail sector, the quest for identification of effective interventions for improving access within hospitals and clinics should be a major priority.

We know practically nothing about ways in which to improve user practices as the majority of evaluations of interventions targeting users have measured only changes in knowledge. We should acknowledge the wealth of evidence that change in knowledge does not necessarily lead to change in practices, and call for measures of change in practices as the relevant outcome of interventions for increasing prompt and effective treatment of improved malaria control.

If in the short term we want to reduce morbidity and mortality from malaria and in the longer term to move towards elimination, sufficient attention needs to be paid to the broader context, particularly health system constraints, that are likely to impact upon the effectiveness and sustainability of interventions to improve prompt and effective treatment, particularly when taken to scale.

Received September 16, 2008. Accepted for publication November 7, 2008.

Acknowledgments: The authors thank Pfizer's Mobilize Against Malaria initiative for providing the funding to support this research.

Disclaimer: The findings, views, and opinions expressed in this article are those of the authors and not of Pfizer Inc.

Authors' addresses: Lucy A. Smith, Disease Control and Vector Biology Unit, Department of Infectious and Tropical Diseases, London School of Hygiene and Tropical Medicine, Keppel Street, London WC1E 7HT, United Kingdom, Tel: +44 (0)207 927 2440, Fax: +44 (0) 207580 9075, E-mail: Lucy.Smith@lshtm.ac.uk. Caroline Jones, Disease Control and Vector Biology Unit, Department of Infectious 
and Tropical Diseases, London School of Hygiene and Tropical Medicine, Keppel Street, London WC1E 7HT, United Kingdom, Tel: +44 (0)207927 2649, Fax: +44 (0) 207580 9075. Sylvia Meek, Malaria Consortium, Development House, 56-64 Leonard Street, London EC2A 4LT, United Kingdom, Tel: +44 (0)20 7549 0210, Fax: +44 (0)20 7549 0211. Jayne Webster, Disease Control and Vector Biology Unit, Department of Infectious and Tropical Diseases, London School of Hygiene and Tropical Medicine, Keppel Street, London WC1E 7HT, United Kingdom, Tel: +44 (0)207 927 2648, Fax: +44 (0) 2075809075.

\section{REFERENCES}

1. Snow RW, Craig M, Deichmann U, Marsh K, 1999. Estimating mortality, morbidity and disability due to malaria among Africa's non-pregnant population. Bull World Health Organ 77: 624-640.

2. Bill and Melinda Gates Foundation, 2007. Opening and Foundation's Vision for Malaria. Malaria Forum-Day 2. Seattle.

3. RBM, 2008. The Global Malaria Action Plan: For a Malaria-free World. Geneva: Roll Back Malaria Partnership.

4. RBM, 2005. Global Strategic Plan: Roll Back Malaria 2005-2015. Geneva: Roll Back Malaria Partnership.

5. WHO, 2008. World Malaria Report 2008. Geneva: World Health Organization.

6. WHO, 1993. Global Srategy for Malaria Control. Geneva: World Health Organization.

7. Williams HA, Jones CO, 2004. A critical review of behavioural issues related to malaria control in sub-Saharan Africa: what contributions have social scientists made? Soc Sci Med 59: 501-523.

8. Brugha R, Zwi A, 1998. Improving the quality of private sector delivery of public health services: challenges and strategies. Health Policy Plan 13: 107-120.

9. Goodman C, Brieger W, Unwin A, Mills A, Meek S, Greer G, 2007. Medicine sellers and malaria treatment in sub-Saharan Africa: what do they do and how can their practice be improved? Am J Trop Med Hyg 77: 203-218.

10. Gyapong M, Garshong B, 2007. Lessons Learned in Home Management of Malaria: Implementation Research in Four African Countries. Geneva: WHO.

11. Ross-Degnan D, Laing R, Santoso B, Ofori-Adjei D, Lamoureux $\mathrm{C}$, Hogerzeil H, 1997. Improving pharmaceutical use in primary care in developing countries: a critical review of experience and lack of experience. International Conference on Improving Use of Medicines. Chiang Mai, Thailand.

12. Habicht JP, Victora CG, Vaughan JP, 1999. Evaluation designs for adequacy, plausibility and probability of public health programme performance and impact. Int J Epidemiol 28: 10-18.

13. RBM, 2000. Framework for Monitoring Progress and Evaluationg Outcomes and Impact. Geneva: Roll Back Malaria Partnership.

14. Armstrong Schellenberg J, Bryce J, de Savigny D, Lambrechts T, Mbuya C, Mgalula L, Wilczynska K, 2004. The effect of Integrated Management of Childhood Illness on observed quality of care of under-fives in rural Tanzania. Health Policy Plan 19: 1-10.

15. Gouws E, Bryce J, Habicht JP, Amaral J, Pariyo G, Schellenberg JA, Fontaine O, 2004. Improving antimicrobial use among health workers in first-level facilities: results from the multicountry evaluation of the Integrated Management of Childhood Illness strategy. Bull World Health Organ 82: 509-515.

16. Ajayi IO, Browne EN, Garshong B, Bateganya F, Yusuf B, AgyeiBaffour P, Doamekpor L, Balyeku A, Munguti K, Cousens S, Pagnoni F, 2008. Feasibility and acceptability of artemisininbased combination therapy for the home management of malaria in four African sites. Malar J 7: 6.

17. Obua C, Ogwal-Okeng JW, Waako P, Aupont O, Ross-Degnan D, 2004. Impact of an educational intervention to improve prescribing by private physicians in Uganda. East Afr Med $J$ (Suppl): S17-S24.

18. Ofori-Adjei D, Arhinful DK, 1996. Effect of training on the clinical management of malaria by medical assistants in Ghana. Soc Sci Med 42: 1169-1176.

19. Tavrow P, Rennie W, 2004. Neighbour-to-Neighbour Education to Improve Malaria Treatment in Households in Bungoma District,
Kenya. Operations Research Results Bethesda: Quality Assurance Project.

20. Winch PJ, Bagayoko A, Diawara A, Kane M, Thiero F, Gilroy K, Daou Z, Berthe Z, Swedberg E, 2003. Increases in correct administration of chloroquine in the home and referral of sick children to health facilities through a community-based intervention in Bougouni District, Mali. Trans R Soc Trop Med Hyg 97: 481-490.

21. Yeboah-Antwi K, Gyapong JO, Asare IK, Barnish G, Evans DB, Adjei S, 2001. Impact of prepackaging antimalarial drugs on cost to patients and compliance with treatment. Bull World Health Organ 79: 394-399.

22. Ansah EK, Gyapong JO, Agyepong IA, Evans DB, 2001. Improving adherence to malaria treatment for children: the use of prepacked chloroquine tablets vs. chloroquine syrup. Trop Med Int Health 6: 496-504.

23. Greer G, Akinpelumi A, Madueke L, Plowman B, Fapohunda B, Tawfik Y, Holmes R, Owor J, Gilpin U, Clarence C, Lennox B, 2004. Improving Management of Childhood Malaria in Nigeria and Uganda by Improving Practices of Patent Medicine Vendors. Arlington, Va: BASICS II for the US Agency for International Development.

24. Kaona FA, Tuba M, 2003. Improving ability to identify malaria and correctly use chloroquine in children at household level in Nakonde district, Northern Province of Zambia. Malar J 2: 43.

25. Kofoed PE, Lopez F, Aaby P, Hedegaard K, Rombo L, 2003. Can mothers be trusted to give malaria treatment to their children at home? Acta Trop 86: 67-70.

26. Nkuo Akenji TK, Ntonifor NN, Ching JK, Kimbi HK, Ndamukong KN, Anong DN, Boyo MG, Titanji VP, 2005. Evaluating a malaria intervention strategy using knowledge, practices and coverage surveys in rural Bolifamba, southwest Cameroon. Trans R Soc Trop Med Hyg 99: 325-332.

27. Nsimba SE, 2007. Assessing the impact of educational intervention for improving management of malaria and other childhood illnesses in Kibaha District-Tanzania. East Afr J Public Health 4: $5-11$.

28. Nsungwa-Sabiiti J, Peterson S, Pariyo G, Ogwal-Okeng J, Petzold MG, Tomson G, 2007. Home-based management of fever and malaria treatment practices in Uganda. Trans $R$ Soc Trop Med Hyg 101: 1199-1207.

29. Okonkwo PO, Akpala CO, Okafor HU, Mbah AU, Nwaiwu O, 2001. Compliance to correct dose of chloroquine in uncomplicated malaria correlates with improvement in the condition of rural Nigerian children. Trans $R$ Soc Trop Med Hyg 95: 320-324.

30. Pagnoni F, Convelbo N, Tiendrebeogo J, Cousens S, Esposito F, 1997. A community-based programme to provide prompt and adequate treatment of presumptive malaria in children. Trans $R$ Soc Trop Med Hyg 91: 512-517.

31. Tavrow P, Shabahang J, Makama S, 2003. Vendor-to-vendor education to improve malaria treatment by private drug outlets in Bungoma district, Kenya. Malar J 2: 10.

32. Tawfik Y, Nsungwa-Sabitii J, Greer G, Owor J, Kesande R, PrysorJones S, 2006. Negotiating improved case management of childhood illness with formal and informal private practitioners in Uganda. Trop Med Int Health 11: 967-973.

33. Marsh VM, Mutemi WM, Willetts A, Bayah K, Were S, Ross A, Marsh K, 2004. Improving malaria home treatment by training drug retailers in rural Kenya. Trop Med Int Health 9: 451-460.

34. Afenyadu GY, Agyepong IA, Barnish G, Adjei S, 2005. Improving access to early treatment of malaria: a trial with primary school teachers as care providers. Trop Med Int Health 10: 1065-1072.

35. Bradley J, Igras S, 2005. Improving the quality of child health services: participatory action by providers. Int J Qual Health Care 17: 391-399.

36. Tavrow P,Shabahang J,Makama S, 2002. Vendor-to-Vendor Education to Improve Malaria Treatment by Drug Outlets in Kenya. Operations Research Results. Bethesda: Quality Assurance Project.

37. Menon A, Joof D, Rowan KM, Greenwood BM, 1988. Maternal administration of chloroquine: an unexplored aspect of malaria control. J Trop Med Hyg 91: 49-54.

38. Griffiths M, 1990. Using anthropological techniques in program design: successful nutrition education in Indonesia, in Anthropology and Primary Health Care, Coreil J, Mull J, eds. Boulder, CO: Westview Press. 
39. Yoder PS, 1997. Negotiating relevance: belief, knowledge, and practice in international health projects. Med Anthropol $Q$ 11: 131-146.

40. Marsh VM, Mutemi WM, Muturi J, Haaland A, Watkins WM, Otieno G, Marsh K, 1999. Changing home treatment of childhood fevers by training shop keepers in rural Kenya. Trop Med Int Health 4: 383-389.

41. Abuya TO, Mutemi W, Karisa B, Ochola SA, Fegan G, Marsh V, 2007. Use of over-the-counter malaria medicines in children and adults in three districts in Kenya: implications for private medicine retailer interventions. Malar J 6: 57.

42. Conteh L, Stevens W, Wiseman V, 2007. The role of communication between clients and health care providers: implications for adherence to malaria treatment in rural Gambia. Trop Med Int Health 12: 382-391.

43. Ogwal-Okeng JW, Obua C, Waako P, Aupont O, Ross-Degnan D, 2004. A comparison of prescribing practices between public and private sector physicians in Uganda. East Afr Med J (Suppl): S12-S16.

44. Djimde A, Plowe CV, Diop S, Dicko A, Wellems TE, Doumbo O, 1998. Use of antimalarial drugs in Mali: policy versus reality. Am J Trop Med Hyg 59: 376-379.

45. Fogg C, Bajunirwe F, Piola P, Biraro S, Checchi F, Kiguli J, Namiiro P, Musabe J, Kyomugisha A, Guthmann JP, 2004. Adherence to a six-dose regimen of artemether-lumefantrine for treatment of uncomplicated Plasmodium falciparum malaria in Uganda. Am J Trop Med Hyg 71: 525-530.

46. Kachur SP, Khatib RA, Kaizer E, Fox SS, Abdulla SM, Bloland PB, 2004. Adherence to antimalarial combination therapy with sulfadoxine-pyrimethamine and artesunate in rural Tanzania. Am J Trop Med Hyg 71: 715-722.

47. Homedes N, Ugalde A, 2001. Improving the use of pharmaceuticals through patient and community level interventions. Soc Sci Med 52: 99-134.

48. Yeung S, White NJ, 2005. How do patients use antimalarial drugs? A review of the evidence. Trop Med Int Health 10: 121-138.

49. Eriksen J, Nsimba SE, Minzi OM, Sanga AJ, Petzold M, Gustafsson LL, Warsame MY, Tomson G, 2005. Adoption of the new antimalarial drug policy in Tanzania-a cross-sectional study in the community. Trop Med Int Health 10: 1038-1046.
50. Biritwum RB, 2001. Impact of health care financing reforms on the management of malaria in Ghana. East Afr Med $J$ 78: 636-640.

51. Chandler CI, Jones C, Boniface G, Juma K, Reyburn H, Whitty CJ, 2008. Guidelines and mindlines: why do clinical staff over-diagnose malaria in Tanzania? A qualitative study. Malar J 7: 53.

52. Osterholt DM, Rowe AK, Hamel MJ, Flanders WD, Mkandala C, Marum LH, Kaimila N, 2006. Predictors of treatment error for children with uncomplicated malaria seen as outpatients in Blantyre district, Malawi. Trop Med Int Health 11: 1147-1156.

53. Rowe AK, Hamel MJ, Flanders WD, Doutizanga R, Ndoyo J, Deming MS, 2000. Predictors of correct treatment of children with fever seen at outpatient health facilities in the Central African Republic. Am J Epidemiol 151: 1029-1035.

54. Rowe AK, Onikpo F, Lama M, Deming MS, 2003. Risk and protective factors for two types of error in the treatment of children with fever at outpatient health facilities in Benin. Int J Epidemiol 32: 296-303.

55. Zurovac D, Rowe AK, Ochola SA, Noor AM, Midia B, English M, Snow RW, 2004. Predictors of the quality of health worker treatment practices for uncomplicated malaria at government health facilities in Kenya. Int $J$ Epidemiol 33: 1080-1091.

56. Rowe AK, de Savigny D, Lanata CF, Victora CG, 2005. How can we achieve and maintain high-quality performance of health workers in low-resource settings? Lancet 366: 1026-1035.

57. Zurovac D, Ndhlovu M, Sipilanyambe N, Chanda P, Hamer DH, Simon JL, Snow RW, 2007. Paediatric malaria case-management with artemether-lumefantrine in Zambia: a repeat crosssectional study. Malar J 6: 31 .

58. McCombie SC, 1996. Treatment seeking for malaria: a review of recent research. Soc Sci Med 43: 933-945.

59. Haines A, Sanders D, Lehmann U, Rowe AK, Lawn JE, Jan S, Walker DG, Bhutta Z, 2007. Achieving child survival goals: potential contribution of community health workers. Lancet 369: 2121-2131.

60. Orton L, Barnish G, 2005. Unit-dose packaged drugs for treating malaria. Cochrane Database Syst Rev CD004614. 